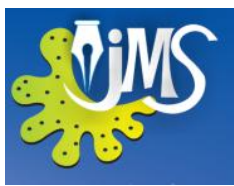

\title{
Effect of central obesity on serum lipid profile in non-diabetic, non-hypertensive subjects - A preliminary study
}

\author{
Kasuni Walatara, Fathima Nusha, Anusha Kaneshapillai, \\ Lohini Athiththan, Rasika Perera, Usha Hettiaratchi \\ Department of Biochemistry, \\ University of Sri Jayewardenepura, Sri Lanka.
}

\begin{abstract}
Central obesity is a significant risk factor for metabolic syndrome in adults. Central fat distribution greatly alters the lipid profile and induces atherogenic dyslipidaemia even in normoglycaemic, non-hypertensive subjects. Hence, the aim of the present study was to identify the serum lipid parameters which are altered with central obesity in non-diabetic, non-hypertensive subjects in Sri Lanka. A cross-sectional study was conducted at the Family Practice Centre of University of Sri Jayewardenepura, after obtaining ethical clearance and informed written consent from 227 non-diabetics, non-hypertensive subjects who were not on Statins. Overnight fasting venous blood was collected and assayed for serum lipid profile such as triglycerides (TG), total cholesterol (TC) and high density cholesterol (HDL). Low density cholesterol (LDL) and TG/HDL ratio were calculated. Waist circumference (WC) was measured based on WHO and NHANES standards. All data were analysed using SPSS (ver.17) software. Mean age of the subjects was $40.7 \pm 13.7$ years and $59.9 \%$ were females. Obese males and females were $40.7 \%$ and $49.3 \%$ respectively. In the study sample, mean TG and TG/HDL ratio were significantly $(p<0.05)$ higher in obese males. However, all mean serum lipid parameters such as TG, TC, LDL and TG/HDL ratio were higher in both obese males and females and HDL was lower in them. Hence, even in non-diabetic, non-hypertensive subjects, central obesity has a relationship with altered lipid profile which could lead to obesity related metabolic abnormalities.
\end{abstract}

Keywords: central obesity, triglycerides, waist circumference. 


\section{INTRODUCTION}

Obesity; excessive accumulation fat in the body, has reached epidemic proportions globally. It is mainly due to an increase in the energy intake than the energy expenditure (Mukhopadhyay, S. K. 2012). Overweight and obesity are known as the fifth leading risk for global deaths and is linked with noncommunicable diseases (NCD) (World Health Organization 2007). The prevalence of NCD is rapidly increasing in developing countries and according to World Health Organization, NCD will account for approximately three quarters of deaths in these countries by the year 2020 (Kelishadi R).

It was estimated that approximately 1.6 billion people in the world, were overweight and at least 400 million adults were obese in 2005. The incidence of overweight and obesity were at peak in the United States (62\%) and lowest in South East Asia (14\%) (World Health Organization 2007). In all regions women were more likely to be obese than men. In Sri Lanka, in 2000 and $2006 / 7$ around $24 \%$ and $31.2 \%$ of women were found to be overweight respectively. A study carried out in 2005/6 revealed that the prevalence of overweight for both genders among adults was 25.2\% (Jayatissa, R., Hossain, S.M.M., Gunawardana S. et al 2012).

Obesity has been associated with an increased risk for metabolic syndrome (MS) in adults. MS is a constellation of metabolic and medical abnormalities, clustered in individuals with upper body fat distribution who often show insulin resistance. Among these abnormalities are hyperinsulinaemia with diabetes and raised fasting plasma glucose, abdominal obesity, and dyslipidaemic profile characterized by a high plasma triglyceride (TG) concentration and low high density lipoprotein cholesterol (HDL) level (Crepaldi, G., Maggi, S. 2006). Central distribution of body fat, particularly intra-abdominal fat is more a risk factor for obesity related ill health than sub-cutaneous distribution (Mishra, N., Sharma, M. K., Chandrasekar, M. 2012).

Obesity can be assessed using several anthropometric measurements and indices. Waist Circumference (WC) with ethnic specific values is considered as the key component of the MS definition and it can be used to assess the metabolic risk associated with intraabdominal fat (Crepaldi, G., Maggi, S. 2006). Within the last 20 years, rapidly rising rates of obesity have led to major increases in the prevalence of type 2 diabetes (T2D) and cardiovascular diseases. Obese people are more likely to have abnormal lipid profile; increasing the risk of atherosclerosis. Increased prevalence, earlier onset, and augmented complications of T2D and cardiovascular diseases are often seen with higher WC in South Asians than in white Caucasians (Chakrewarthy, S., Gunasekera, D., Pathmeswaren A. et al 2006).

Abnormal lipid profile has long been suspected to contribute to atherogenic dyslipidaemia, which describes the combination of raised TG and low concentrations of HDL cholesterol together with elevated apolipoprotein B. Low HDL cholesterol and high TG levels are considered as major components of the definition for the MS given by International Diabetic Federation (IDF) (Vishwanath, P., Prashant, A., Acharya A. 2012). These are independently atherogenic and 
they are commonly observed in people with both central obesity and T2D. Overweight and obese people had significantly high $\mathrm{TG}$, total cholesterol (TC) and low density lipoprotein (LDL) cholesterol (Thakur, J. S., Bisht, S. 2010). Indian obese people were found to have high TG, TC and LDL and low HDL than nonobese (Puavilai, W., Laoragpongse, D. 2004). Hence, obesity alone is a major independent risk factor for altered lipid profile giving rise to atherogenic dyslipidaemia.

Obesity induced diseases are diagnosed only after symptoms appear and many people are unaware that it alone could gives rise to atherogenic dyslipidaemia which is a major abnormality of metabolic syndrome. Therefore early detection would be a pre-alarming sign before the onset of developing obesity induced diseases and it would be of significant value to the individuals to overcome the risk of getting diseases. Even though obesity prevalence is high in Sri Lanka, people are unaware that central obesity alone could give rise to atherogenic lipid profile. Hence, the aim of this study was to identify the altered serum parameters with central obesity in non-diabetic, non-hypertensive subjects in Sri Lanka.

\section{MATERIALS AND METHODS}

\section{a. Study population and sampling}

This study was conducted as a cross-sectional study, at the Family Practice Centre, University of Sri Jayewardenepura (USJP) involving 227 non-diabetic $\quad(\mathrm{FPG}<5.9 \mathrm{mmol} / \mathrm{L})$, nonhypertensive subjects, between 20-70 years of age. The study was approved by the Ethics Review Committee of USJP and informed written consent was obtained from all the participants prior to the study.

\section{b. Measurements}

After an overnight fasting period (12 hours), venous blood samples were collected from each subject. The parameters of the lipid profile (TC, TG and HDL) were measured based on the Beer Lambert law using Stanbio ${ }^{\circledR}$ kits involving an enzymatic method. LDL was calculated using the Friedwald equation as given below.

$$
\text { LDL-C }=\text { TC }-\mathrm{HDL}-[\mathrm{TG} / 5]
$$

(The use of Triglyceride/5 indicates that all of the plasma TG is carried on VLDL-C and TG/ cholesterol ratio of VLDL-C is constant at about 5:1 [11]).

WC of each subject was measured using a non-stretchable measuring tape. Participants were asked to stand with arms at sides, feet positioned close together, in a relaxed posture while breathing naturally. The measurement was made at the approximate midpoint between the lower margin of the last palpable rib and the crest of the ileum (top of the hip bone), placing the non-stretchable tape around the trunk in a horizontal plane. The tape was parallel to the floor and it was without compressing the skin. The measurement was made at the end of a normal expiration to the nearest $0.1 \mathrm{~cm}$ (Lui, A. 2008).

\section{c. Definitions}

The results were arranged based on the definition of MS according to the IDF criteria given below:

1. Central obesity ; for males $>90 \mathrm{~cm}$ and for females $>80 \mathrm{~cm}$

2. Raised triglycerides $>150 \mathrm{mg} / \mathrm{dL}$

3. Low HDL - cholesterol $<40 \mathrm{mg} / \mathrm{dL}$ 
Those presented with central obesity together with above two criteria were considered as having MS.

All the subjects were categorised into subgroups depending on the classification given by the Adults Treatment Panel III (Mekki, N., Christofilis, M. A., Charbonnier, M. et al 1999), Aziz, J., Siddiqui, A. N., Siddiqui, I. A., Omai,

A.

2003). 
Table 1. Classification of serum lipid parameters

\begin{tabular}{lll}
\hline Lipid parameter & Concentration & Classification \\
\hline Serum triglycerides & $<150 \mathrm{mg} / \mathrm{dL}$ & Normal \\
& $150-199 \mathrm{mg} / \mathrm{dL}$ & Borderline high \\
& $\geq 200 \mathrm{mg} / \mathrm{dL}$ & High \\
& $<40 \mathrm{mg} / \mathrm{dL}$ & Low \\
HDL cholesterol & $\geq 60 \mathrm{mg} / \mathrm{dL}$ & High \\
& $<100 \mathrm{mg} / \mathrm{dL}$ & Normal \\
LDL cholesterol & $100-129 \mathrm{mg} / \mathrm{dL}$ & Near optimal \\
& $\geq 130 \mathrm{mg} / \mathrm{dL}$ & high \\
& $\leq 2$ & Low \\
TG/HDL ratio & $>2.1$ & High \\
& &
\end{tabular}

\section{d. Statistical analysis}

All data were double-entered and cross checked for consistency. Data were analysed using Statistical Package for Social Science (SPSS) software (Ver. 17). All the analysis was carried out for males and females separately. Descriptive statistical results were presented as means \pm standard deviations. Independent sample t-Test was used to assess the significant differences among obese and non-obese groups. In all statistical analyses a p-value $<0.05$ was considered as significant.

\section{RESULTS}

Among 227 subjects, 91 were males and 136 were females. Mean \pm SD of the sample characteristics are mentioned in table 2 .

According to the classification of WC based on the metabolic risk level (Lakka, H. M., Lakka, T. M., Tuomilehto, et al J 2002), among the males $40.7 \%$ were obese and $49.3 \%$ of the females were obese. Obese males' TG was at a borderline high level whereas LDL was slightly above the normal (Mekki, N., Christofilis, M. A., Charbonnier, M. et al 1999) TG/HDL ratio in both males and females were at the risk level Aziz, J., Siddiqui, A. N., Siddiqui, I. A., Omai, A. 2003).

Table 2. Mean \pm SD values of the study sample

\begin{tabular}{lll}
\cline { 2 - 2 } Table & Characteristics & \multicolumn{1}{c}{ Mean \pm SD } \\
\cline { 2 - 3 } Mean & Age (years) & $40.7 \pm 13.7$ \\
& Waist circumference $(\mathrm{cm})$ & $83.6 \pm 11.0$ \\
& Total cholesterol $(\mathrm{mg} / \mathrm{dL})$ & $188.6 \pm 42.5$ \\
& Triglycerides $(\mathrm{mg} / \mathrm{dL})$ & $124.8 \pm 71.8$ \\
& High density lipoprotein cholesterol $(\mathrm{HDL})(\mathrm{mg} / \mathrm{dL})$ & $49.7 \pm 13$ \\
& Low density lipoprotein cholesterol $(\mathrm{LDL})(\mathrm{mg} / \mathrm{dL})$ & $114.1 \pm 42.3$ \\
& Triglyceride/HDL ratio & $2.8 \pm 1.9$ \\
\hline
\end{tabular}

3. lipid 
parameters of males and females based on waist circumference

* Differences are significant at $\mathrm{p}<0.05$.

\begin{tabular}{lllllll}
\hline & WC group & $\mathrm{TC}(\mathrm{mg} / \mathrm{dL})$ & $\mathrm{TG}(\mathrm{mg} / \mathrm{dL})$ & $\mathrm{HDL}(\mathrm{mg} / \mathrm{dL})$ & $\mathrm{LDL}(\mathrm{mg} / \mathrm{dL})$ & $\mathrm{TG} / \mathrm{HDL} \mathrm{ratio}$ \\
\hline Males & $<90 \mathrm{~cm}$ & 181.5 & $\mathbf{1 1 6 . 8}$ & 48.1 & 110.4 & 2.7 \\
& $\geq 90 \mathrm{~cm}$ & 196.8 & $\mathbf{1 6 7 . 6}$ & 45.8 & 118.1 & $3.8^{*}$ \\
\multirow{3}{*}{ Females } & $<80 \mathrm{~cm}$ & 188.5 & $\mathbf{1 1 2 . 2}$ & 51.8 & 114.0 & 2.6 \\
& $\geq 80 \mathrm{~cm}$ & 190 & $\mathbf{1 2 0 . 4}$ & 50.9 & 114.9 & 2.5 \\
\end{tabular}

Table 3 shows the mean values of lipid profile variables in obese and non-obese males and females according to the WC cut off values. When different lipid parameters were compared with WC, cut off values for obese and nonobese individuals, obese males and females had high TC, TG, LDL and TG/HDL ratio and low HDL than non-obese subjects, but the difference was significant only in males, for TG and TG/HDL ratio $(\mathrm{p}<0.05)$.

Our results indicate both obese males and females have higher plasma levels of lipid parameters. Many other studies have also shown that triglycerides accumulation in plasma is higher in obese subjects as well as overproduction of LDL and reduced clearance of the lipid particles [16]. Similarly, a study carried out in Pakistan found that mean TG, TC and LDL levels had a higher risk of getting elevated in obese subjects compared to nonobese subjects even in the absence of cardiometabolic diseases [17].

Male obese subjects are more vulnerable to have altered lipid parameters with metabolic abnormalities. According to literature, higher WC has a twofold risk of metabolic impairments, especially coronary heart diseases in men [18]. A study carried out in Indian males has found that obese subjects with higher WC have an association with altered lipid profiles in terms of TG, TC and LDL (Puavilai, W., Laoragpongse, D. 2004). Our study results support these findings. Thus, central obesity measured by WC has an association with elevated TG levels and TG/HDL ratio and is significant in males.

\section{CONCLUSIONS AND FUTURE WORK}

The present study shows that central obesity is an independent risk factor in causing abnormalities in plasma lipid profile, mainly TG and has a significant effect in males. It changes the TG/HDL ratio which alters HDL levels as well. Therefore, even in the absence of diabetes and hypertension, obese subjects have a high tendency to develop metabolic abnormalities. Hence, simple measurement such as WC could be strongly recommended to be used routinely at medical checkups to detect the risk of developing obesity related metabolic abnormalities and to recommend healthy life style modifications with a proper diet and necessary physical activities. Furthermore, researches are currently being conducted in larger populations on the same topic to ascertain the validity of the present study as applicable to the country. 


\section{REFERENCES}

MUKHOPADHYAY, S. K. (2012). Study of lipid profile in obese individuals and the effect of cholesterol lowering agents on them. Al Ameen. J. Med. Sci. 5 (2), 147151.

WORLD HEALTH ORGANIZATION (2007). http://www.who.int/gho/ncd/risk_factors/ob esity_text/en/, Visited last on 27.04.2014

KELISHADI, R.: Childhood overweight, obesity and the metabolic syndrome in developing countries. Epidemiol Rev. 29, $62-76$.

JAYATISSA， R., HOSSAIN, S.M.M., GUNAWARDANA, S., RANBANDA, J.M., GUNATHILAKA, M. AND DE SILVA, P.C. (2012). Prevalence and associations of overweight among adult women in Sri Lanka: a national survey. Sri Lanka Journal of Diabetes, Endocrinology and Metabolism, 2, 61-68.

CREPALDI, G., MAGGI, S. (2006). The metabolic syndrome. Diabetes Voice, May, 5--39

MISHRA, N., SHARMA, M. K., CHANDRASEKAR, M., SURESH, M., PRASAD, S. V., KONDAM, A. (2012). Central obesity and lipid profile in North Indian Males. International Journal of Applied Biology and Pharmaceutical Technology, 3 (3), 291-294

CHAKREWARTHY, S., GUNASEKERA, D., PATHMESWAREN, A., WIJEKOON, C. N., RANAWAKA, U. K., KATO, N., TAKEUCHI, F., WICKREMASINGHE, A. R. (2006). A comparison between revised NCEP ATP III and IDF definitions in diagnosing metabolic syndrome in an urban Sri Lankan population: the Ragama health study. ISRN Endocrinology, $2013,1--7$ (2013) International Diabetes Federation,
The IDF consensus worldwide definition of the metabolic syndrome, pp. 4--23. IDF comuunications, Belgium (2006)

VISHWANATH, P., PRASHANT, A., ACHARYA, A., SUMA, M.N., KIRAN, H.S., KARTHIK, G. (2012). Use of anthropometric indices as simple predictors of deranged lipid profile and at risk population for future cardiovascular events. Int. J. Health Allied Sci. 1 (1), 8-12.

THAKUR, J. S., BISHT, S. (2010). Blood lipid profile of obese and non-obese sedentary college men. VSRD Tech. \& Non Tech., $1(1), 26-29$.

PUAVILAI, W., LAORAGPONGSE, D. (2004). Is calculated LDL-C by using the new modified Friedewald equation better than the stand Friedewald equation? J. Med. Assoc. Thai., 87 (6), 589-593.

CENTRES FOR DISEASE CONTROL AND PREVENTION (2002). National Health Nutrition Examination Survey, Anthropometry Procedures Manual. pp.1-120. US department of health and human services, Hyattsville , MD (2009) Adult Treatment Panel III: Third report of the National Cholesterol Education Program (NCEP) expert panel on detection, evaluation, and treatment of high blood cholesterol in adults (Adult Treatment Panel III) Final Report. Circulation: J. Am. Heart Assoc., 106, 3143 -421.

LUI, A.(2008). Lipid panel reference range changes. 2nd of November 2011. Pathology, Inc, Torance (2011) World Health Organization, Waist circumference and waist-to-hip ratio; Report of a WHO 
expert consultation, 1--47. WHO document production services, Geneva.

MEKKI, N., CHRISTOFILIS, M. A., CHARBONNIER, M., ATLAN-GEPNER, C., DEFOORT, C., JUHEL, C., BOREL, P., PORTUGAL, H., PAULI, A. M., VIALETTES, B., LAIRON, D. (1999). Influence of obesity and body fat distribution on postprandial lipemia and triglyceride rich lipoproteins in adult women. J. Clin. Endocrinol. Metab., 183190.

AZIZ, J., SIDDIQUI, A. N., SIDDIQUI, I. A., OMAI, A. (2003). Relation of body mass index with lipid profile and blood pressure in young healthy students at Ziauddin Medical University. J. Ayub. Med. Coll. Abbottabad., 15 (4), 57—9.

LAKKA, H. M., LAKKA, T. M., TUOMILEHTO, J., SALONEN, J. T. (2002). Abdominal obesity is associated with increased risk of acute coronary events in men. Eur. Heart J., 23, 706-713. 